\title{
ПАРЛАМЕНТСКИЕ ВЫБОРЫ В ДАНИИ
}

\begin{abstract}
Аннотация. 5 июня 2019 г. в Дании прошли парламентские выборы. Основными темами на них стали: иммиграционная политика, изменение климата и реформирование системь благосостояния. Успешнее других выступила сочиал-демократическая партия, предполагающзая сформировать однопартийное правительство меньшинства. «Красный блок» опередил по числу проголосовавших «синий блок». Крупное поражение потерпела стоящая на позициях национализма Датская народная партия. Председатель СДПД М. Фредериксен в течение трёх недель вела переговоры с союзниками по «красному блоку» о выработке согласованного курса нового правительства. В статье анализируются итоги выборов, рассматривается развитие политической ситуаџии в Дании.

Ключевые слова: Дания, парламентские выборы, иммиграџионная политика, изменение климата, социальная политика, Датская народная партия, Венстре, Социал-демократическая партия Дании.
\end{abstract}

В этом году парламентские выборы в Дании состоялись почти сразу после выборов в Европарламент, которые в местных политических кругах рассматривались как проба сил для парламентских партий страны. И на тех и на других выборах участие населения было высоким: на Евровыборах - 66\%, на выборах в фолькетинг - 84,1\%. Больших неожиданностей выборы 5 июня не принесли: две ведущие соперничающие между собой партии - либеральная Венстре (ПВ) и Социал-демократическая партия Дании (СДПД) получили наибольшее число голосов (23,4 и 25,9\% соответственно). Правда, для социал-демократов результаты выборов были худшими за много лет, они приобрели дополнительно всего один мандат, в то время как партия Венстре - 9 мандатов.

Третья по величине и влиянию - Датская народная партия (ДНП), как это и предрекали предшествовавшие выборам опросы, потерпела крупное поражение, потеряв 21 мандат и набрав всего 8,7\% голосов (на выборах 2015 г. у неё было 37 мандатов и 21,1\% голосов).

Помимо конкуренции между отдельными партиями, налицо острое соперничество «красного блока» (СДПД, Социал-либеральная партия, Социалистическая Народная партия, Красно-зелёный Альянс, Социал-демократическая партия Фарерских островов и гренландская партия Сиумут) с «синим блоком» (буржуазные: Венстре, Либеральный Альянс и Консервативная народная партия, а также поддерживающая их блок в парламенте Датская Народная партия). Первый блок получил 93 мандата, его конкуренты - 76, что дало социал-демократам преимущественное право формировать правительство. Лидер партии М. Фредериксен уже на следующий день после выборов начала переговоры о его составе. Они были интенсивными и длились по датским меркам продолжительное время - три недели (таких длительных переговоров не было с 1988 г.). Незадолго до полуночи 25 июня М. Фредериксен наконец смогла объявить, что партии пришли к соглашению и была создана база для формирования социал-

(C) Плевако Наталия Сергеевна - кандидат исторических наук, руководитель Центра Северной Европы Отдела страновых исследований Института Европы РАН. Адрес: 125009, Россия, Москва, ул. Моховая, д. 11, стр. 3. E-mail: natalia_plevako@mail.ru.

DOI: http://dx.doi.org/10.15211/vestnikieran320194247 
демократического правительства меньшинства. Соглашение на 18 страницах стало основой для его будущих действий, и было охарактеризовано составителями как прогрессивное, справедливое, наступательное и «зелёное» 1.27 июня было сформировано новое правительство страны.

Для Дании правительство меньшинства не редкость, хотя таковое обычно не отличается устойчивостью и срок его правления, как правило, недолог. Социал-демократы ещё до выборов заявили, что в случае победы они предполагают сформировать однопартийное правительство, опирающееся на поддержку других партий блока. Сформировать подобный кабинет министров без Социал-либеральной партии они впервые попробовали в 1993 г. Ныне, по словам М. Фредериксен, перспективы формирования однопартийного правительства связаны с жёсткой иммиграционной политикой её партии, с чем не согласны социал-либералы и часть Красно-зелёного Альянса. В то же время большинство депутатов фолькетинга поддерживают жёсткий курс в отношении мигрантов, и М. Фредериксен в интервью газете «Юлландс пост» фактически дала обещание продолжать его после выборов. «Мы не должны принимать в Дании больше иностранцев, чем можем интегрировать. Важно также, чтобы у правительства были развязаны руки, если будут нужны новые инициативы», заявила она ${ }^{2}$. Социал-демократическая партия в последнее время заметно сдвинулась вправо. Она одобряла строгие иммиграционные законы, принятые предыдущим правительством Л.Л. Расмусена, разрыв между СДПД и «синим блоком» в оценке существующих проблем стал не столь очевиден. Так, в 824 случаях голосования по законопроектам, СДПД более чем в 90\% голосовала за правительственные предложения ${ }^{3}$.

В течение последних трёх лет социал-демократы конструктивно сотрудничали и с ДНП, вызывая всё больше нареканий союзников СДПД по блоку. Правда, отмечают датские исследователи, социал-демократы дорого заплатили за это, теряя голоса избирателей, утекающих к партиям левого спектра.

Сотрудничество этих двух партий, ослабило и Датскую народную партию: голоса избирателей ДНП перешли по большей части к социал-демократам, частично к партии Венстре, а также к более радикальным мелким право-популистским националистическим партиям, таким, как «Жёсткий курс» и «Новые правые». Многие избиратели отвернулись от ДНП, как не готовой нести политическую ответственность и сосредоточенной лишь на критике. В этом смысле повлиял на избирателей и тот факт, что ДНП отказалась в 2015 г. войти в правительство, ограничившись его поддержкой и оставаясь протестной популистской партией. Появление же новых крайне правых националистических партий означало, что её электоральные активы начинают распыляться. К тому же в последнее время резко снизился приток беженцев, и это тоже способствовало падению рейтинга партии. Недовольство избирателей вызывал и тот факт, что ДНП основное внимание уделяла проблемам иммиграции и беженцев, игнорируя, например, такой важнейший, как полагает большинство датчан, вопрос как последствия изменения климата, активно обсуждавшийся в предвыборных дебатах. Лидер партии К.Т. Даль и его предшественница и создатель партии П. Кьерсгорд считают, что обсуждение этих проблем похоже на истерию ${ }^{4}$.

\footnotetext{
${ }^{1}$ Tre stöd partier ger S makten i Danmark. URL: https://www.dn.se/nyheter/varlden/klart-med-ny-dansk-regering/ (дата обращения: 27.06.2019).

2 Cordsen Ch. Mette Frederiksengår till valg på socialdemokratisk+et parti regering. URL: https://www.dr.dk/ nyheder/politik/mette-frederiksen-gaar-til-valg-paa-socialdemokratisk-et-parti-regering (дата обращения: 16.06.2019).

${ }^{3}$ Kampmark B. The Danish Elections: Social Democracy with an Inhumane face. URL: https://www.counterpunch.org/ 2019/06/12/the-danish-elections-social-democracy-with-an-inhumane-face/ (дата обращения: 15.06.2019).

${ }^{4}$ Uppenbart att oron for klimatet väåer bland väljarna. URL: https://www.dn.se/nyheter/varlden/uppenbart-att-oron-forklimatet-vaxer-bland-valjarna/ (дата обращения: 15.05.2019).
}

Научно-аналитический вестник ИЕ РАН, 2019, №3 
Несмотря на сокрушительное поражение на выборах, риторика ДНП оказала сильное влияние на другие партии: и социал-демократы и «синие» откликались на её призывы проводить жёсткую политику по отношению к иммигрантам и беженцам и в программных документах и, главное, в конкретной политической практике. В итоге был введён строгий контроль на границе Дании, сокращён приём беженцев и ищущих убежища людей, уменьшены пособия для них.

После выборов 2019 г. в фолькетинге появилась ещё одна правоконсервативная националистическая партия «Новые правые», набравшая 2,4\% голосов. Её заявления гораздо жёстче риторики ДНП. Она требует вообще остановить приём ищущих убежища и беженцев, отказать имеющимся в стране иммигрантам пользоваться политикой благосостояния, высылать прибывающих в страну беженцев.

Переговоры между партиями «красного блока» заставили социал-демократов несколько смягчить свою позицию по иммиграционному вопросу. Требование продолжить пограничный контроль осталось, но было принято решение принимать в страну беженцев по квоте Евросоюза. В согласительном документе подчёркивалась необходимость интеграции иммигрантов. М. Фредериксен высказывается за уже апробированную на практике идею ДНП высылать мигрантов на родину. П. Кьерсгорд заявила, что она нарушила сделанные перед выборами обещания ${ }^{1}$. В документе также высказано отрицательное отношение к планам высылать на датский остров Линдхольм тех иммигрантов, которые совершили противоправные действия, но которых нельзя отправить на родину из-за ведения там военных действий или острых гражданских конфликтов. При предыдущем буржуазном правительстве были приняты одиозные законы о конфискации денег и драгоценностей у ищущих убежища людей, находящихся в лагерях для беженцев в Дании и ждущих решения своей судьбы, закон об обязанности мусульман соблюдать обычаи Дании, в частности пожимать руку женщине, при вручении ею иммигранту вида на жительство в Дании. Хотя эти законы носили больше формальный характер и редко соблюдались, партии, участвовавшие в переговорах, высказали своё отрицательное отношение к ним и потребовали прекратить их действие.

Проблема иммиграционной политики тесно связана с другой проблемой, активно обсуждавшейся перед выборами - судьбой государства благосостояния и шире - скандинавской модели, которая претерпевает изменения не только в Дании. Несмотря на то что страна всё ещё находится в первых рядах стран с высокими расходами государственного бюджета на социальные нужды, составляющими $28 \%$ от суммы ВНП ${ }^{2}$, общественный сектор потребления, на который приходилась главная доля социальных услуг, всё больше уступает место частной инициативе, что на практике ведёт к дополнительным расходам в семейном бюджете. Особенно активно действует частный сектор в здравоохранении, где действенность и эффективность его услуг выше, чем в государственном секторе. Далеко не всем нравится этот процесс наступления частной инициативы. Видимо, поэтому, несмотря на дрейф социал-демократии вправо, она победила. В силу традиции её рассматривают как главную защитницу интересов трудящихся. Предвыборные обещания М. Фредериксен касались увеличения государственных расходов, налогов на бизнес, реформирования непопулярной пенсионной реформы, проведённой правоцентристским правительством Л.Л. Расмуссена. Видимо, именно это обстоятельство позволило вернуться к власти после продолжительного перерыва и социал-демократам Финляндии.

\footnotetext{
${ }^{1}$ H. Grosshög Nya klimatmåk i danska regeringsavtalet - här är punkterna som sticker ut. URL: https://www.dn.se/ny heter/varlden/nya-klimatmal-i-danska-regeringsavtalet-har-ar-punkterna-som-sticker-ut/ (дата обращения: 27.06.2019). ${ }^{2}$ URL: https://stats.oecd.org/Index.aspx?DataSetCode=SOCX_AGG (дата обращения: 27.06.2019).
} 
Важно отметить одно любопытное обстоятельство: и правоцентристские партии и ДНП, а теперь и социал-демократы связывают спасение государства благосостояния с рестриктивной политикой по отношению к иммигрантам и беженцам, ибо именно в них видят незаконных потребителей социальных благ. Приезжающие иностранцы не должны сразу требовать социальных льгот, считают они. Ещё недавно социал-демократы настаивали на укреплении интеграционного процесса в стране главным образом с помощью экономических стимулов. Поэтому сокращались пособия по безработице. Как пишет политолог О.Г. Агустин, М. Фредериксен «полагает, что утрата доверия к социал-демократии объясняется не только её неолиберальной экономической политикой, но и либеральной миграционной политикой партии» ${ }^{1}$. Это в значительной степени объясняет причины отхода социал-демократов от либеральных позиций и сближения с идеями Датской народной партии в вопросе иммиграции. Однако такой поворот в политике не всегда находит одобрение со стороны союзников СДПД по блоку, поэтому переговоры с ними были нелёгкими, и, ища точки соприкосновения, стороны настаивали на взаимных уступках. В договоре, заключённом между партиями «красного блока», даны обещания увеличить социальные расходы на бедных, прежде всего детей, введения дополнительного пособия на их нужды, увеличения числа обслуживающего персонала детских садов, реформирования системы здравоохранения.

Ещё одной проблемой, которая активно обсуждалась перед выборами, стало изменение климата и мер по предотвращению последствий этого процесса. Скандинавские страны традиционно обращают много внимания экологическим проблемам, которые здесь подчас решаются успешнее, чем в других странах, но проблема, по всей видимости, приобретает новое качество. Тема климата впервые в истории парламентских выборов выдвинулась на политическую авансцену ${ }^{2}$. На фоне экстремально высоких температур прошлого лета и засухи сыграл свою роль так называемый «эффект Греты» ${ }^{3}$. Отличительной чертой нынешних дебатов по этому вопросу стала активизация молодёжи, которая принимает участие в дискуссиях, демонстрациях, акциях протеста, обвиняя нынешних политиков в бездействии и неспособности практически решать проблемы климата. Большое внимание этой проблеме уделяли средства массовой информации. В результате практически все политические партии в большей или меньшей степени включили в свои программные установки тематику зелёных партий. Традиционные экологические партии не всегда оказывались от этого в выигрыше. Так, потеряла голоса на парламентских выборах партия окружающей среды в Швеции, социал-либеральная датская экологическая партия Альтернатива не смогла получить мандат в Европарламент и преодолеть барьер для прохождения в фолькетинг. Достаточно заметные противоречия присутствовали и среди партий «красного блока». Социал-демократы говорят о необходимости сократить выбросы парниковых газов на 60\% к 2030 г., считая с 1990 г. Остальные три партии блока ставят целью сокращение на $70 \%$, и это являлось предметом серьёзных обсуждений ${ }^{4}$. В конечном итоге победила точка зрения трёх поддерживающих СДПД партий. Важным требованием программы был запрет с 2030 г. на продажу автомобилей, использующих дизельное топ-

\footnotetext{
1 Danes first, Welfare last. URL: https://www.jacobinmag.com/2019/01/denmark-social-democrats-immigrationwelfare (дата обращения: 17.06.2019).

${ }^{2}$ Согласно опросам, в январе 2019 г. проблемы изменения климата считали важнейшими $22 \%$ избирателей, весной - уже 60\%. Uppenbart att oron för klimatet väåer bland väljarna. URL: https://www.dn.se/nyheter/varlden/uppen bart-att-oron-for-klimatet-vaxer-bland-valjarna/ (дата обращения: 15.06.2019).

${ }_{3}^{3}$ Шведская школьница Грета Тюнберг (15 лет) начала активную кампанию, критикуя власти за бездействие в борьбе против изменения климата. Её выступления получили широкий резонанс в других странах, накануне выборов в Дании прошла демонстрация с её участием.

4 Jensen T.K. Groene ambitioner giver store uenigheder mellem socialdemokratiet og stotte partierne. URL: https://www.dr.dk/nyheder/politik/folketingsvalg/groenne-ambitioner-giver-store-uenigheder-mellem-socialdemokra tiet-og (дата обращения: 17.06.2019).
}

Научно-аналитический вестник ИЕ РАН, 2019, №3 
ливо и бензин. Кроме того, партии вступили с инициативой борьбы с пластиковыми отходами и улучшения качества питьевой воды. При этом и та и другая сторона признают, что проблема финансирования «зелёной конверсии» является наиболее сложной, и она далека от завершения.

Итак, парламентские выборы в Дании принесли победу «красному блоку» во главе с сильнейшей партией социал-демократов. 25 июня договорённость между партиями этого блока по вопросу формирования правительства была достигнута. Комментаторы говорят о полевении политических настроений в Дании. Однако позиция СДПД в вопросе приёма иммигрантов и близость её с идеями Датской народной партии, однозначно не подтверждает эти выводы. Всё будет зависеть от возможностей и силы союзников по блоку воздействовать на лидеров социал-демократии в этом вопросе. Скорее всего, для сохранения своего правительства социал-демократы будут стараться делать им уступки. Но если учесть, что жёсткую линию в иммиграционной политике поддерживает большинство партий фолькетинга, достичь компромисса будет нелегко. Что касается «климатической повестки дня», то давление экологистов ожидается достаточно сильным. Однако её осуществление, так же как и социальной составляющей, будет определяться чисто экономическими возможностями. Л.Л. Расмуссен уже высказался по поводу договора своих оппонентов, назвав его «красно-зелёным списком пожеланий», который «не подкреплён финансированием и не конкретен»1 .

Выборы в Дании, как и в других странах Северной Европы, показывают, что политическая ситуация здесь остаётся стабильной. Представляется также, что националисты достигли высшего предела своей активности и влияния. Можно также сделать вывод о прочности демократических институтов: новые оппозиционные партии и общественные организации не остаются вне этих институтов, а очевидно превращаются в системную оппозицию и становятся нормально функционирующим разрядом политического класса.

\section{Список литературы}

История Дании. Под редакцией С. Буска и Х. Поульсена. М., 2007.

Могунова М.А. Скандинавский парламентаризм: теория и практика. М., 2001.

Современные избирательные системы. Вып. 4: Австралия, Венесуэла, Дания, Сербия. Т.И. Чурсина, А.Г. Орлов, И.А. Ракитская, К.А. Половченко; науч. ред. А.В. Иванченко, В.И. Лафитский. М., РЦОИТ: Ин-октаво, 2009. 480 с.

\section{References}

Cordsen Ch. Mette Frederiksengår till valg på socialdemokratisk et parti regering URL: https://www.dr.dk/nyheder/politik/mette-frederiksen-gaar-til-valg-paa-socialdemokratisk-et-partiregering (дата обращения: 16.06.2019).

Danes first, Welfare last. URL: https://www.jacobinmag.com/2019/01/denmark-social-demo crats-immigration-welfare (дата обращения: 17.06.2019).

Istoriya Danii. Pod redaktsiyey S. Buska i KH. Poul'sena. M., 2007.

Jensen T.K. Grooene ambitioner giver store uenigheder mellem socialdemokratiet og stotte partierne. URL: https://www.dr.dk/nyheder/politik/folketingsvalg/groenne-ambitioner-giver-storeuenigheder-mellem-socialdemokratiet-og (дата обращения: 17.06.2019).

\footnotetext{
${ }^{1}$ H. Grosshög Nya klimatmåk i danska regeringsavtalet - här är punkterna som sticker ut. URL: https://www.dn.se/ny heter/varlden/nya-klimatmal-i-danska-regeringsavtalet-har-ar-punkterna-som-sticker-ut/ (дата обращения 27.06.2019).
}

Научно-аналитический вестник ИЕ РАН, 2019, №3 
Kampmark B. The Danish Elections: Social Democracy with an Inhumane face. URL: https:// www.counterpunch.org/2019/06/12/the-danish-elections-social-democracy-with-an-inhumane-face/ (дата обращения: 15.06.2019).

Mogunova M.A. Skandinavskiy parlamentarizm: teoriya i praktika. M., 2001.

Sovremennyye izbiratel'nyye sistemy. Vyp. 4: Avstraliya, Venesuela, Daniya, Serbiya. T.I. Chursina, A.G. Orlov, I.A. Rakitskaya, K.A. Polovchenko; nauch. red. A.V. Ivanchenko, V.I. Lafitskiy. M., RTSOIT: In-oktavo, 2009. 480 s.

Uppenbart att oron for klimatet väåer bland väljarna. URL: https://www.dn.se/nyheter/varlden/ uppenbart-att-oron-for-klimatet-vaxer-bland-valjarna/ (дата обращения: 15.05.2019).

\section{Parliamentary Elections in Denmark}

Author. Natalia Plevako, Candidate of Sciences (History), Head of the Centre for Northern Europe Studies, Department for Countries Researches, Institute of Europe, Russian Academy of Sciences. Address: 11-3, Mokhovaya str., Moscow, Russia, 125009. E-mail: natalia_plevako@mail.ru.

Abstract. The parliamentary elections were held in Denmark June 5.2019. The main topics were: immigration policy, climate change and reform the welfare system. More successful than others was the social democratic party, which intends to form a one-party minority government. «Red block» was ahead of the «blue block» by the number of voters. The Danish People's party, standing on the positions of nationalism, suffered a major defeat. Chairman of the SDPD M. Frederiksen for three weeks was negotiating with the allies on the «red block» on the development of an agreed course of the new government. The article analyzes the results of the elections, the development of the political situation in Denmark.

Keywords: Denmark, parliamentary elections, immigration policy, climate changes, Danish people's party, Venstre, Social democratic party of Denmark.

DOI: http://dx.doi.org/10.15211/vestnikieran320194247 